\title{
OPTICAL FIBRE CONNECTORS FOR HARSH ENVIRONMENTS
}

\author{
J.C. CHALLANS \\ Plessey Connectors Limited, Northampton, England. \\ (Received December 1, 1982; in final form March 21, 1984)
}

This paper describes the construction of a multiway Optical Fibre connector suitable for harsh environments, based on a ruggedised marine connector (Patt 608) shell, and employs expanded-beam principles. The connector utilises an array of sapphire sphere lenses force-fitted into a metal plate forming a flat mating surface with all the precision parts protected behind the lenses.

\section{INTRODUCTION}

The rapid development of Fibre Optics, coupled with the successful installation of Fibre Optic systems around the world, is increasing the demand for demountable Fibre Optic connectors. Users are now looking for more than a demountable splice and are demanding connectors that also meet their handling, environmental and economic requirements.

In particular, military and industrial users require connectors with very high reliability to work at the extremes of environmental conditions. The connector will be disconnected frequently and will not be treated with great care.

Plessey Connectors is actively involved in several major military programmes developing the use of Fibre Optics. This paper describes the construction of multiway optical connectors based on a ruggedised marine connector (Patt 608) shell employing the Expanded-beam principle. This connector is very robust and environmentally sealed, and has no delicate spring loaded precision parts in the mating components, and the mating surface is manufactured to reasonable machining tolerances. The ruggedness is achieved at the expense of about $1 \mathrm{~dB}$ increase in loss and in a tighter angular tolerance.

\section{EXPANDED-BEAM PRINCIPLES}

In an Expanded-beam connector ${ }^{1}$ the light radiated from the end of the fibre is collomated by a lens in one half of the connector and is then refocussed on a fibre end by the lens in the other half of the connector (Figure 1). The advantages of this arrangement are that the allowable lateral displacements between the connector halves are the same fraction of the beam diameter as that of the fibre core in a butt connector, i.e. a maximum of $10 \%$, and the gap between the lenses

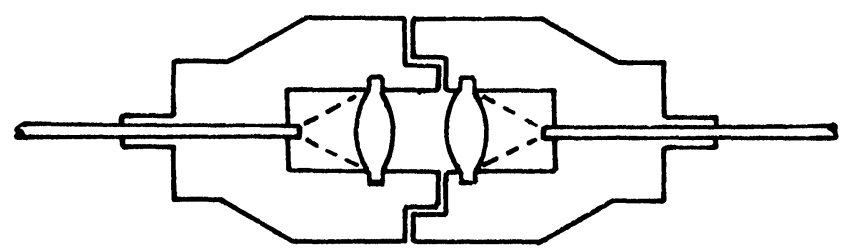

FIGURE 1 Expanded-beam connector. 
can be several millimetres. As previously stated, there are now no delicate spring loaded precision parts to intermate, which may become jammed or damaged. The relaxation of the lateral tolerances is offset by a tightening of the angular tolerances.

\section{COUPLING EFFICIENCY}

The coupling efficiency of the Expanded-beam connector is dependent upon the alignment of the fibre behind the lens, the spherical aberration of the lens and the reflections of the various lens surfaces. The alignment tolerances behind the lens are the same as betweeen the fibre ends in a butt connector due to the 1-1 confocal lens arrangements. Ray tracing ${ }^{2}$ and experiments indicate that for sphere lenses, the spherical aberrations will increase connector losses by $0.4-1.1 \mathrm{~dB}$. The reflections at the interface between the fibre and the lens can be removed by the use of an index matching material.

\section{DESIGN TARGET}

The initial design called for a connector that could be used for field deployment, was very rugged, could withstand a tensile load of $2000 \mathrm{~N}$ and could be easily cleaned. The loss had to be better than $3.0 \mathrm{~dB}$ over the temperature range $-55^{\circ} \mathrm{C}$ and $+80^{\circ} \mathrm{C}$ with large core Plastic Clad Silica fibre. The connector had to be capable of being terminated in the field without the aid of epoxy bonding or polishing and no alignment or focussing adjustment was permitted. Later additions to the specification included the use of small core all silica fibre which could be epoxy bonded and polished. Some degree of fibre focussing was permitted.

\section{CONNECTOR CONSTRUCTION}

Various forms of lenses have been used successfully in Expanded-beam connectors. These include sphere lenses, ${ }^{3}$ rod lenses, ${ }^{4}$ and GRIN rod lenses ${ }^{5}$ (Figure 2).

Sphere lenses have been used at Plessey Connectors for the majority of the developments, mainly sapphire sphere lenses. These were chosen because

a) sapphire is the second hardest commonly available material known to man and is thus very difficult to scratch;

b) they are readily available to high tolerances (less than 1 micron) over a wide range of diameters;
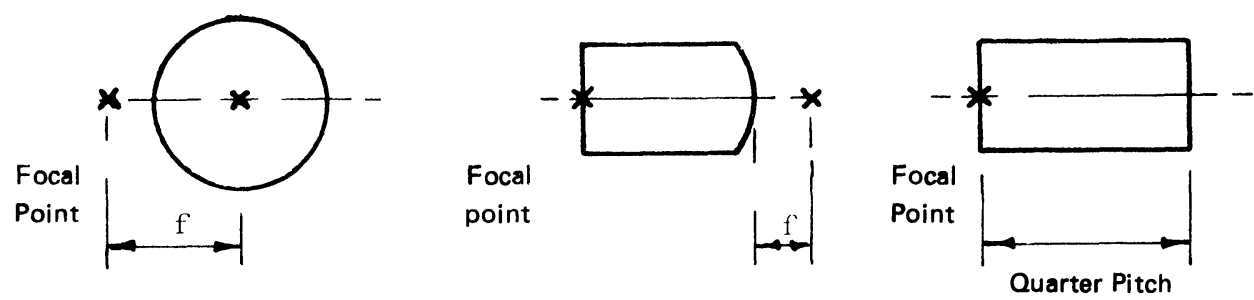

FIGURE 2 Possible lenses for Expanded-beam connectors - a) Sphere Lens, b) Rod lens, and c) GRIN Rod lens. 


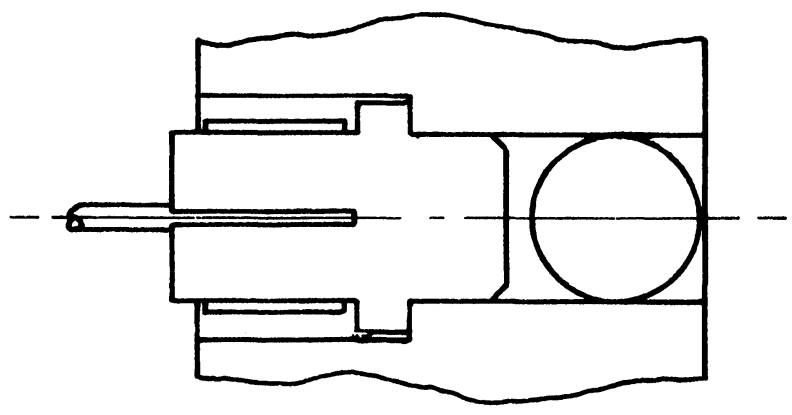

FIGURE 3 Cross-section of expanded-beam connector.

c) except for a small degree of birefringence, the optical axis is the same as the mechanical axis, thus allowing for easy alignment of the fibre behind the lens. (As sapphire is slightly birefringent, it has proved beneficial to use glass spheres for very small core fibres.)

The sapphire spheres are fixed into the connector by force fitting them into a hole jig bored to form a matrix on the connector mating surfaces (Figure 3). The fibre is fixed in a ferrule which is a close fit in the hole behind the lens. With plastic coated silica fibre, the fibre is clamped or crimped into the ferrule and the end cleaved proud of the ferrule end. All silica fibre must be bonded into the ferrule and the fibre end polished, either to a special length in a jig or fitted into a ferrule which will permit focussing. The space between the lenses and the fibre ends is filled with a deformable silicon rubber index matching pad. The separation of the spheres is slightly more than their diameters but is not very critical.

Multiway connectors (2, 4 and 12 way) in Patt 608 shells (Figures $4 \& 5$ ) have been constructed by replacing the rubber insert in the standard connector by a

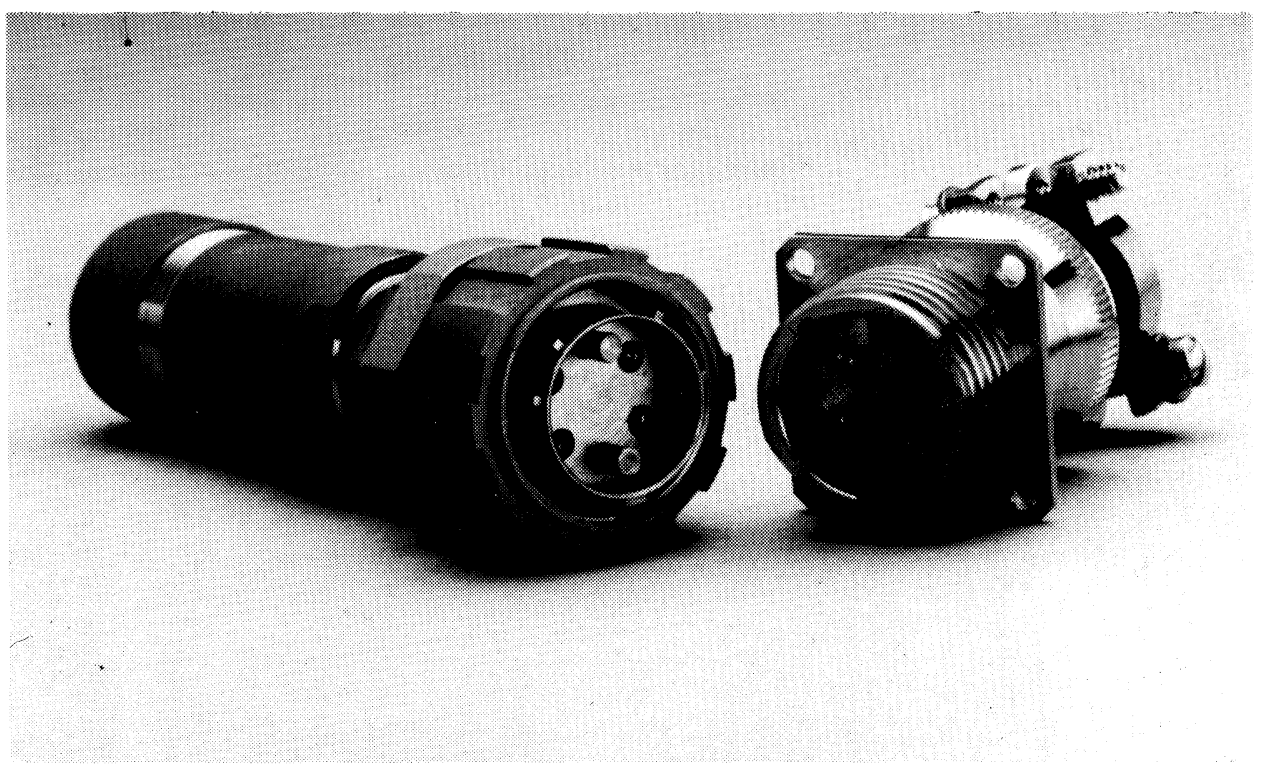

FIGURE 4 4-way expanded-beam connector. 


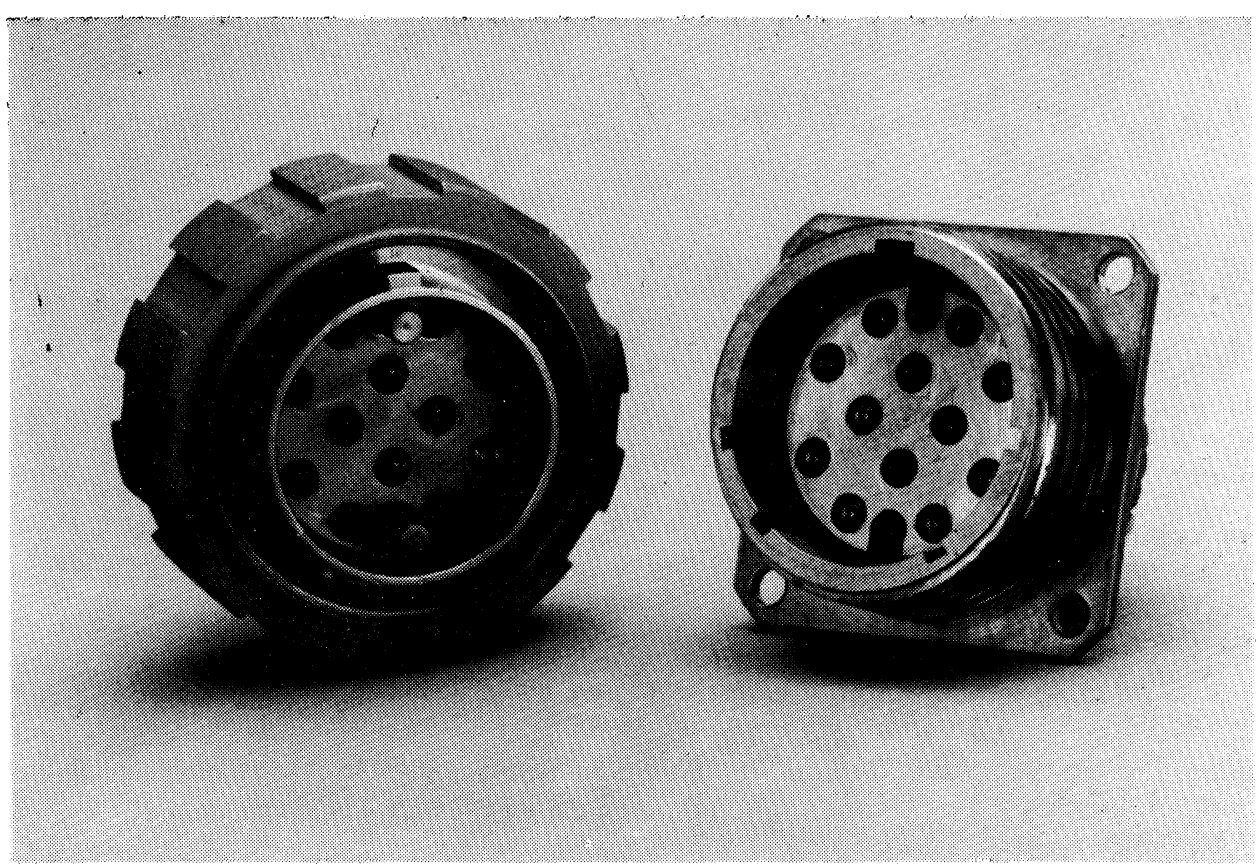

FIGURE 5 12-way Expanded-beam connector.

metal disc. A matrix of holes is jig-bored into which the spheres are force-fitted. This results in a flat, water-tight surface which is easily cleaned. Alignment pins are fitted to ensure correct alignment of the two connector halves.

\section{EXPERIMENTAL RESULTS}

\subsection{Loss}

Sphere lenses of various diameters and several types of fibre were used in development. The losses measured are noted below. The final choice of lens diameter was taken on space considerations.

Fibre

400 um PCS

400 um PCS

250 um PCS

250 um PCS

200/250 um All Glass

200/300 um All Silica

100/140 um All Silica
Lens Diameter

$4.0 \mathrm{~mm}$

$3.5 \mathrm{~mm}$

$3.5 \mathrm{~mm}$

$3.0 \mathrm{~mm}$

$3.0 \mathrm{~mm}$

$3.0 \mathrm{~mm}$

$3.0 \mathrm{~mm}$
Loss $\mathrm{dB}$

2.0

2.5

2.5

2.0

2.5

\subsection{Temperature}

When temperature cycled between $-55^{\circ} \mathrm{C}$ and $+80^{\circ} \mathrm{C}$ no change in loss was noted with All Silica or All Glass fibre. With PCS fibre, a change of $-0.5 \mathrm{~dB}$ was noted at $-55^{\circ} \mathrm{C}$. 


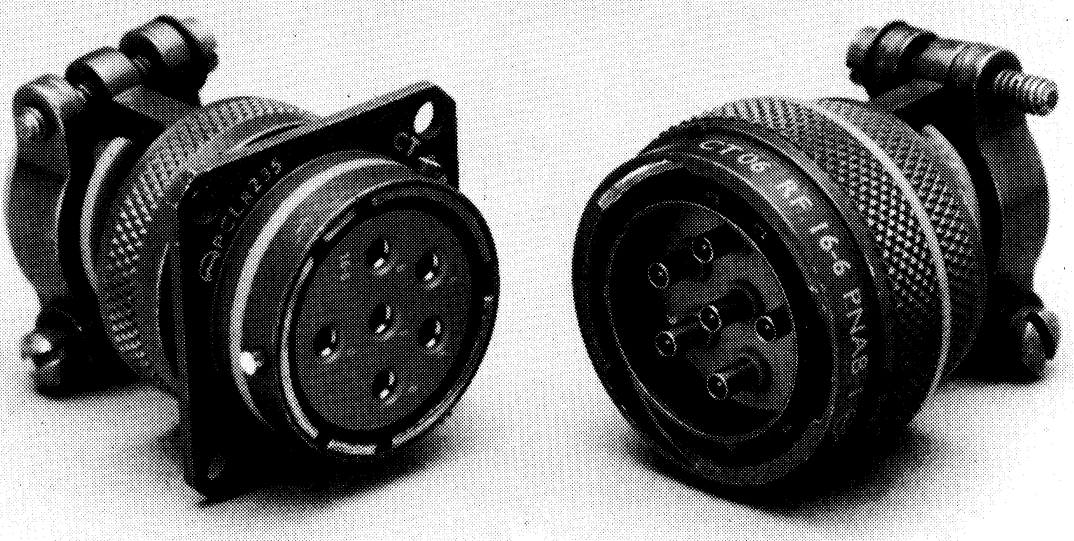

FIGURE 6 Expanded-beam pins in MIL-C-38999 connector.

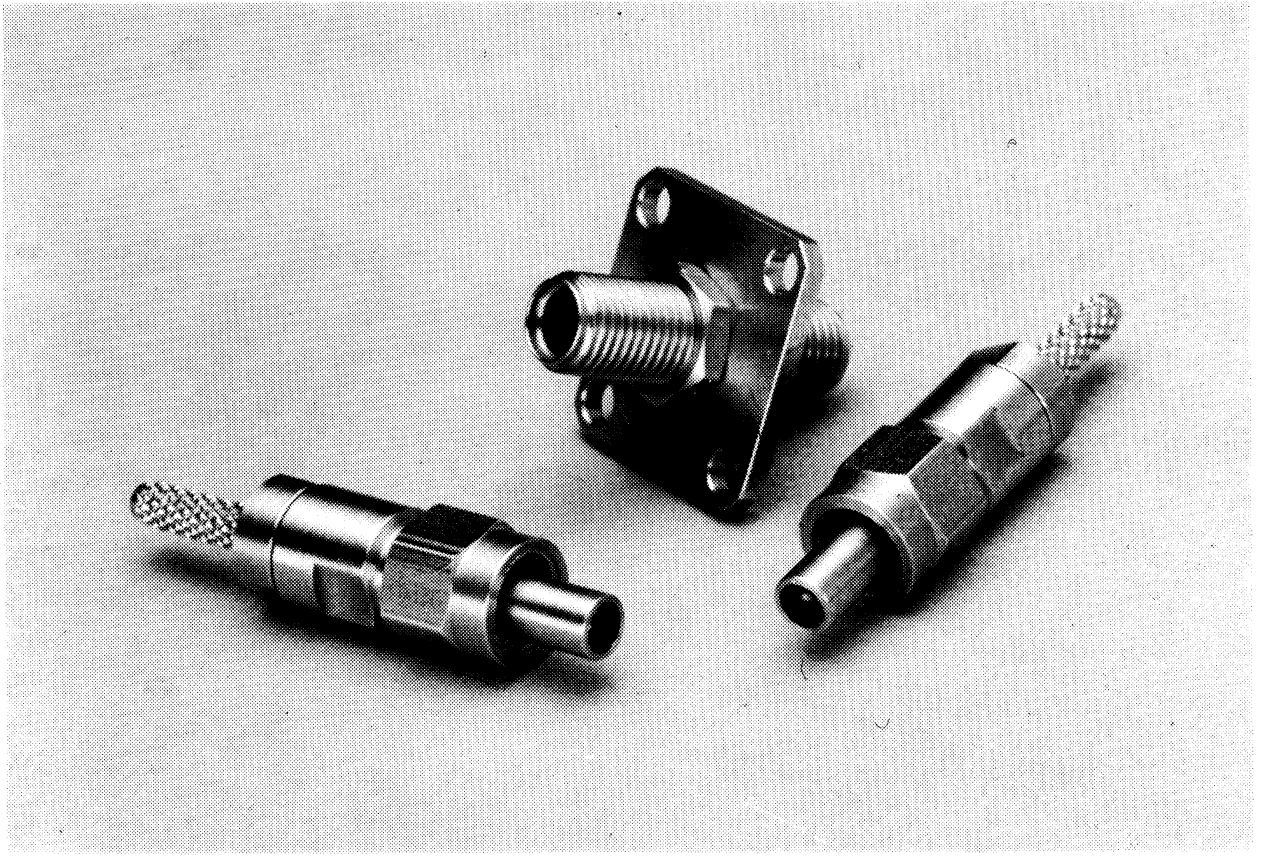

FIGURE 7 S.M.A. style Expanded-beam connectors. 


\subsection{Tensile Load}

Using the braid clamp of a Patt 608 connector, it was found possible to anchor a cable containing an external strength member of $12 \times 1420$ denier Kevlar yarns to withstand a tensile load of $2000 \mathrm{~N}$.

\section{OTHER APPLICATIONS}

Expanded-beam connectors have been constructed, as optical contacts, for MIL-C26482 and MIL-C-38999 (Figure 6) and as an SMA type connector (Figure 7). Use has been made of the fact that the lenses of the connector are spaced several millimeters apart to construct a ' $T$ ' coupler. In this coupler a partial reflecting mirror is inserted into the beam to couple out some light for use with data busses etc. This form of coupler is non mode-dependent and can have a lower loss than a fused taper coupler if total connector loss is included. Alternatively, a dichroic filter in the beam will form a simple wavelength multiplexer.

\section{CONCLUSIONS}

Expanded-beam techniques enable the construction of rugged, environmental sealed optical fibre connectors that can be used in harsh conditions. The connectors are capable of many thousands of operations and can be cleaned with ease.

\section{ACKNOWLEDGEMENTS}

The author thanks his many colleagues at Plessey Connectors Limited, Plessey Research (Caswell) Limited, and Plessey Electronics Systems Research Limited, Southleigh, for their valuable assistance, and to the Directors of Plessey Connectors Limited for permission to present this paper.

\section{REFERENCES}

1. D.A. Kahn, British Patent Number 1429843.

2. J.C. Baker and D.N. Payne, "Expanded-beam Connector Design study", Applied Optics Vol 20, no. 16 pp 2861-1867 (15th August 1981).

3. J.P. Dakin and W. Stewart, British Patent Number 2002136B.

4. J.C. Routh and J.H. Stewart, "Rod Lens Conenctor for Optical Fibres", 5th European Conference on Optical Communication, Amsterdam (1979).

5. J.S. Leach, A.B. Harding, P.R. Cooper, M.J. Cook, "A Rugged Optical Fibre Connector for use in Field Conditions". FOC.80, San Francisco, USA. 

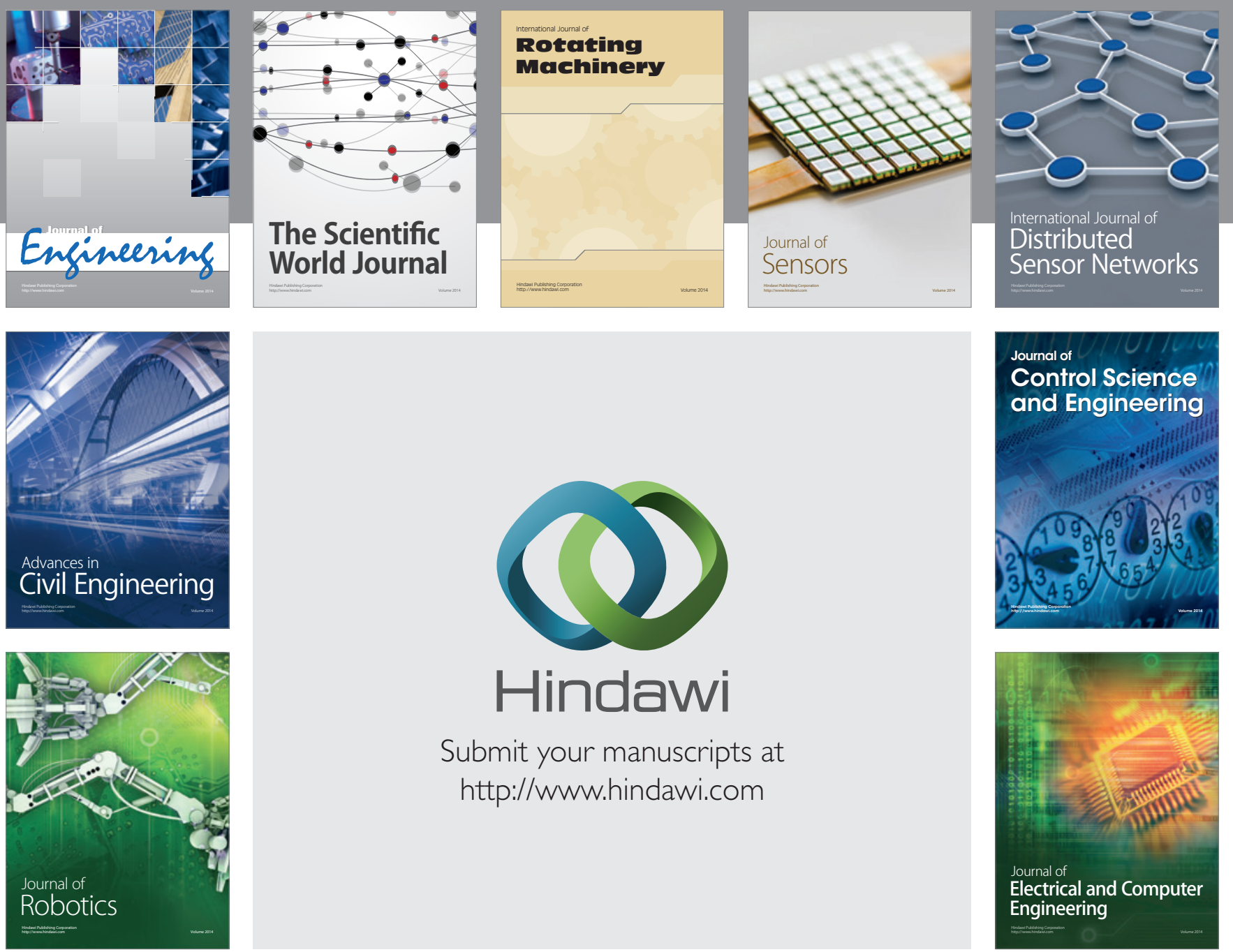

Submit your manuscripts at

http://www.hindawi.com
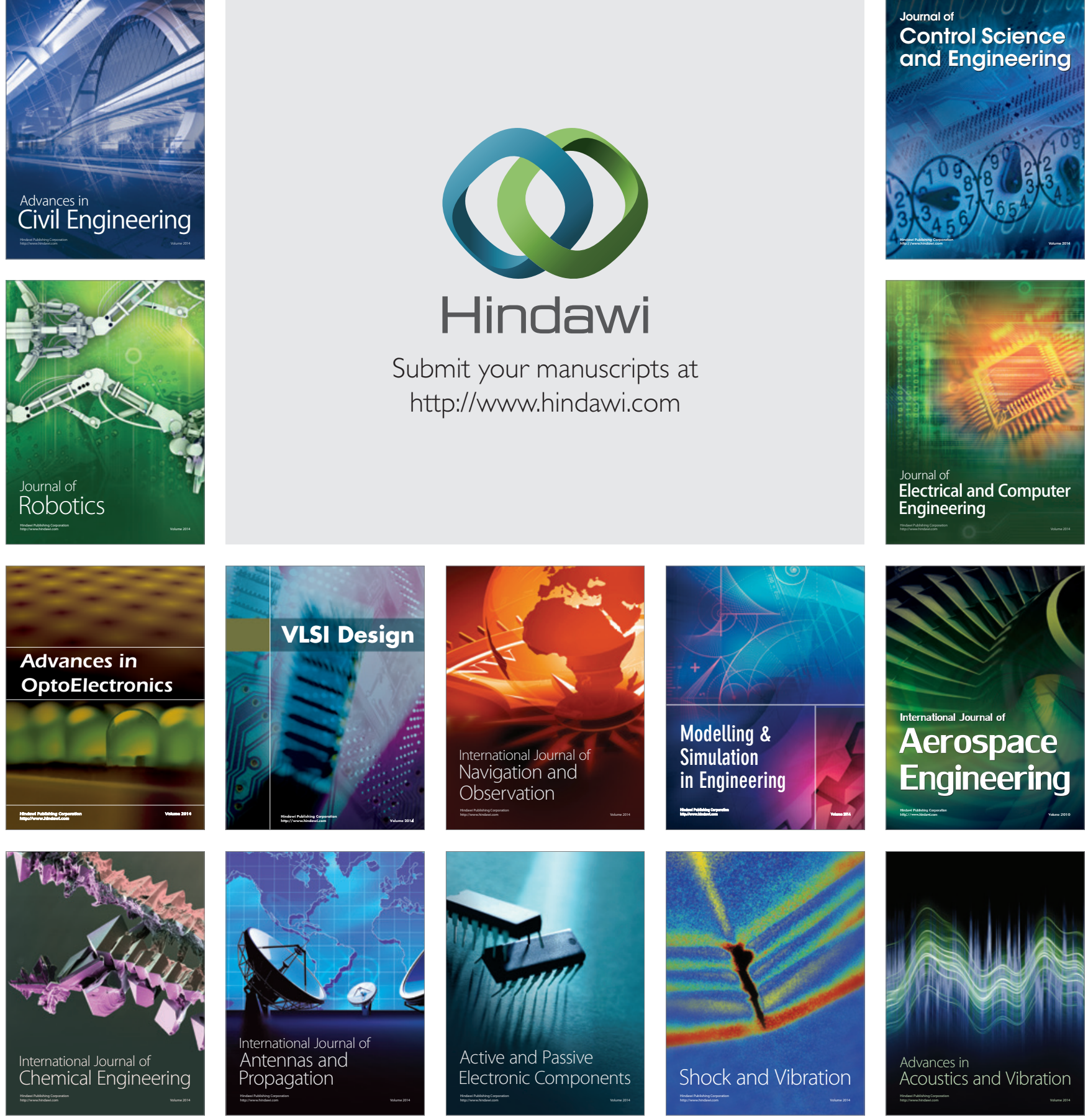